\title{
PrÁCTICAS SOCIOCULTURALES, TURISMO E IDENTIDAD ENTRE LOS HIJOS DE MIGRANTES YUCATECOS EN CANCÚN
}

\author{
Sociocultural Practices, Tourism and Identity among the Children of Yucatecan Migrants in Cancun
}

\author{
Pedro Antonio Be-Ramírez \\ Eyder Gabriel Sima-Lozano \\ Adriana González-Neri
}

\begin{abstract}
Resumen: El centro turístico de Cancún en el sur de México atrae a muchas familias migrantes mayas originarias de la región maicera al este de la península yucateca, un área donde las tradiciones ceremoniales y rituales se conservan. En el nuevo escenario social, la transmisión de prácticas y valores indígenas a las nuevas generaciones estáen tensión constante con el contexto turístico de la ciudad. Desde la perspectiva de los hijos de las familias migrantes, este artículo se enfoca en el rol de la cultura may a para dar significado a las prácticas y construcciones sociales que ofrecen un sentido de congruencia a las vidas. Entre los jóvenes existen nuevas formas de interpretary apropiarse de su "herencia yucateca maya".
\end{abstract}

Palabras clave: migración interna, migración rural-urbana, migrantes, cultura maya, prácticas socioculturales, identidad.

Abstract: Southern Mexico's commercialized tourist hub Cancun draws many working migrant Mayan Indian families whose origins are based in the Eastern corn-growing region of Yucatán, an area wh. In their new social scenario, the transmission of social y cultural practices, norms and values to new generations is in constant tension with the surrounding touristic social context. From the perspective of children of migrant families, this article focuses on the roll that Mayan Culture plays in signifying practices and constructs, which offer congruency and a sense of place to their lives. Among young people there are new ways of understanding, interpreting and appropriating their "Yucatecan Mayaheritage".

Keywords: internal migration, rural-urban migration, migrants, Mayan culture, social and cultural practices, identity.

Pedro Antonio Be Ramírez. Doctor en Antropología por la Universidad Nacional Autónoma de México. Profesor-investigador en la Facultad de Ciencias Humanas, Universidad Autónoma de Baja California, Campus Mexicali, México. Temas de especialización: estudios sobre migración interna e internacional, identidad, etnicidad, sexualidad, género y turismo. Correo electrónico: pedro.be.ramirez@gmail.com. Eyder Gabriel Sima Lozano. Doctor en Antropología por la Universidad Nacional Autónoma de México. Profesor-investigador en la Facultad de Idiomas, Universidad Autónoma de Baja California, Campus Ensenada, México. Temas de especialización: sociolingüística de la lengua maya, procesos de mantenimiento y desplazamiento de lenguas indígenas, actitudes lingüísticas, pragmática de textos argumentativos. Correo electrónico: eyderg@gmail.com.
Adriana González Neri. Maestra en Ciencias de la Educación por el Instituto de Estudios Universitarios, Plantel Cancún, México. Profesora en la Universidad del Caribe (UNICARIBE), México. Temas de especialización: turismo de salud, desarrollo humano, educación, aprendizaje, salud y género. Correo electrónico: adriana_ neri@hotmail.com.

Enviado a dictamen: 15 de agosto de 2016.

Aprobación: 8 de mayo de 2017.

Revisiones: 1 . 


\section{Introducción}

$\mathrm{D}$ esde los inicios del Plan Maestro Cancún y la conformación de esta ciudad hace más de cuarenta años, han llegado a ella oleadas de inmigrantes procedentes de todo el país, especialmente de Yucatán. En la ciudad, desarrollada bajo una óptica centrada en el turismo, la segunda generación de migrantes yucatecos ${ }^{1}$ se enfrenta hoy día a una doble socialización: en primer lugar a la tensión entre el conjunto de valores, costumbres y tradiciones transmitidos a través del entorno doméstico y la comercialización de dichas prácticas para el consumo turístico, y, en segundo lugar, al conjunto de aprendizajes colectivos propios de la sociedad mayor. En esta encrucijada es donde se ponen en juego las representaciones culturales e identitarias de los jóvenes radicados en Cancún puesto que en su cotidianidad viven en un ámbito de contradicción constante.

El objetivo de este escrito consiste en comprender cómo se insertan estos jóvenes con padres de origen yucateco en los múltiples escenarios donde interactúan en la ciudad de Cancún, las prácticas domésticas que realizan con respecto a algunos rituales mayas o a otras costumbres como la preparación de platillos regionales yucatecos, así como su relación con el sector turístico, entre otros aspectos que configuran su "mundo de vida", sobre todo en la construcción social de la identidad. Para alcanzar este objetivo nos planteamos las siguientes interrogantes: icuáles son las prácticas socioculturales que los jóvenes radicados en Cancún realizan con respecto a lo yucateco y lo maya?, ¿qué prácticas de la comercialización de la cultura maya intervienen en el contexto cancunense y qué expresan los jóvenes sobre ello? y, finalmente, ¿cómo construyen los jóvenes su identidad a través de la experiencia en su lugar de origen y en el escenario actual?

A partir de un estudio de caso sobre las experiencias de jóvenes cuyos padres proceden de la región maicera del oriente de Yucatán será posible advertir cómo se perciben estos procesos socioculturales al situarse en un espacio turístico. La información que aquí se presenta corresponde a una investigación más amplia relacionada
PRÁCTICAS SOCIOCULTURALES, TURISMO E IDENTIDAD ENTRE LOS HIJOS DE MIGRANTES YUCATECOS EN CANCÚN

con el vínculo que guarda la segunda generación de migrantes yucatecos en Cancún con el turismo, así como los impactos sociales, culturales, económicos y políticos de la actividad turística sobre la ciudad, al ser este sector parte fundamental de su desarrollo y crecimiento continuos. Sin duda, Cancún es el polo turístico por excelencia del estado de Quintana Roo, y muy importante en el país, además de ser un lugar de encuentro de inmigrantes de diferentes latitudes.

El contenido de este documento se compone de un apartado sobre la conceptualización de la identidad como cambiante, dinámica y contrastiva en un determinado grupo o colectividad. En la siguiente sección, dividida en dos apartados, se efectúa una caracterización de la zona de procedencia de los migrantes yucatecos en los que nos centramos, la maicera, y también del lugar actual o de destino donde residen los informantes, la ciudad de Cancún. El tercer apartado consta de tres partes; en la primera mostramos las experiencias de los jóvenes y cómo interactúan y se retroalimentan entre sí con respecto a las prácticas socioculturales, costumbres y tradiciones yucatecas; en la segunda analizamos la comercialización de la cultura maya desde el ámbito turístico y, finalmente, en la tercera nos referimos a su configuración identitaria. Concluimos el trabajo con unas reflexiones finales en las que discutimos cómo la socialización de los hijos, con múltiples elementos transmitidos por sus padres, pone en la discusión la multiplicidad de sus pertenencias en el marco de una economía basada en el turismo.

\section{La identidad, emblema de contrastes}

Como construcción social, la identidad surge como producto de los intercambios que realizan las personas a partir de su propia subjetividad con otros individuos en el marco del contexto en el que participan. Así, en el sentido planteado por Barth (1976) la identidad siempre incluye un elemento contrastivo pues implica una relación entre nosotros y ellos y la existencia de dos o más identidades relacionadas que pueden ser confrontadas para, con base en esas distinciones, afirmar lo propio en oposición a lo ajeno. Si partimos 
Pedro antonio Be-Ramírez, Eyder Gabriel Sima-Lozano, ADRIANA GONZÁLEZ-NERI

de una realidad construida socialmente a partir de la interacción y la toma de diversas decisiones y reajustes de las personas, esto nos lleva a establecer, tal como asegura Bartolomé, que la identidad "es un concepto polisémico que alude a fenómenos múltiples, ya que no hay un ser sino formas del ser" (2006: 42). Por tanto, la identidad debe comprenderse como un proceso histórico-social cambiante y ligado a contextos específicos.

Esta identificación o pertenencia al grupo como un fenómeno subjetivo, y por ende cognitivo, nos permite identificarnos e identificar a los miembros de nuestro propio grupo para generar una afirmación identitaria en función del contraste con "el otro significativo". La pertenencia a un colectivo, grupo o comunidad entraña compartir lo que Giménez denomina "el complejo simbólico-cultural” (1997: 14), pues encierra un contenido distintivo sea simbólico, material o emocional hacia dicha colectividad. Con ello su pertenencia implica, al menos de manera parcial, compartir el núcleo de representaciones sociales, los discursos, los textos y lo simbólico, que otorgan distinción y les caracterizan.

Así, para Giménez "lo simbólico es el mundo de las representaciones sociales materializadas en formas sensibles [o simbólicas], y que pueden ser expresiones, artefactos, acciones, acontecimientos y alguna cualidad o relación" (2007: 32), es decir, va desde la fonética o la escritura, hasta las prácticas sociales, los usos y costumbres, la indumentaria, la alimentación, la vivienda y la organización del espacio y del tiempo, entre otros elementos. Por ello, lo simbólico, para este autor, envuelve todo el extenso conjunto de procesos sociales basados en la significación, así como en la comunicación. La realidad social es dotada de significado por el grupo, y ésta se reconstruye cognitivamente e integra a su sistema de creencias y valores otros significados acordes al contexto social, histórico e ideológico donde se sitúa.

En la construcción social de la identidad existen aspectos destacables o sobresalientes de la personalidad que el individuo elige expresar u ocultar en consonancia con el entorno y lo situacional. En el marco de esta caracterización propia y de los otros, se establecen los lineamientos de la identificación, diferenciación
PRÁCTICAS SOCIOCULTURALES, TURISMO E IDENTIDAD ENTRE LOS HIJOS DE MIGRANTES YUCATECOS EN CANCÚN

o reinvención como procesos simultáneos en un grupo o colectividad. Para Oehmichen (2005), una colectividad cultural puede transitar entre el abandono o readaptación de sus elementos socioculturales y el cambio cultural al interior del mismo grupo por el contacto entre dos o más culturas y, así, generar transformaciones significativas. En ese sentido, el cambio cultural en un grupo ocurre al estar éste sujeto a procesos de modernidad o globalización entre otros aspectos históricos, económicos o políticos.

Aquí vale preguntarse sobre las estrategias que los grupos emplean para mantenerse, persistir o reelaborar sus experiencias de vida, de tal suerte que hoy en día los límites son porosos y cambiantes, lo que da paso a la oportunidad de reconstruirse. Esto puede observarse entre los yucatecos o mayas yucatecos, ${ }^{2}$ cuyos elementos o emblemas identitarios son resultado de esa capacidad de refuncionalizarse a razón de apropiar, integrar e interpretar esquemas, prácticas o rasgos ajenos a su matriz cultural (Bartolomé, 2006; Guzmán, 2005). Esta capacidad de reinventarse, de dar sentido a un nuevo modo de vida en un escenario de migración interregional y de construcción social de la identidad, puede observarse en una de las regiones yucatecas más tradicionales y con una importante participación migratoria: la maicera.

\section{Una mirada a los escenarios de origen y destino}

\section{La región maicera de Yucatán ${ }^{3}$}

La llamada región maicera o milpera del oriente yucateco está compuesta por veinticinco municipios considerados de gran tradición cultural. En la época colonial se caracterizó por la sublevación, la resistencia y la huida de sus pobladores, lo que, junto con la vegetación tropical, hizo que la región fuera considerada poco accesible y hospitalaria para los españoles, por lo que la presencia de éstos fue menos nutrida en la zona que en el resto de la entidad yucateca (Guzmán, 2005; Lewin, 2007). Localizada en la región centro-norte del estado de Yucatán, la zona maicera: “es quizá la región más tradicional en cuanto a prácticas ceremoniales y 
Pedro Antonio Be-Ramírez, Eyder Gabriel SimA-Lozano, ADRIANA GONZÁLEZ-NERI
PRÁCTICAS SOCIOCULTURALES, TURISMO E IDENTIDAD ENTRE LOS HIJOS DE MIGRANTES YUCATECOS EN CANCÚN rituales" en la entidad, como lo señalan Quintal et al. (2003: 296). La continuidad histórica y cultural que la ha caracterizado otorga sentido a las formas particulares de comprender su mundo de vida.

Los movimientos de huida y repoblamiento fueron las primeras llamaradas de resistencia, como la ocurrida en el poblado de Tekax en 1610 o la protagonizada por Jacinto Canek en 1761 en el poblado de Cisteil. Estos movimientos constituyeron las bases de los principios ideológicos y políticos que desencadenaron en la región del oriente yucateco la confrontación de los indígenas rebeldes contra la aristocracia "blanca yucateca" en la llamada Guerra de Castas (Dumond, 2005; Guzmán, 2005). Quienes continuaron en la lucha y aquellos que aceptaron los privilegios e incentivos supuestamente recibidos por la élite gobernante (Quintal, 2005) sacaron provecho de ese momento en el que existía una mínima presencia de los blancos, sobre todo en el oriente.

Un hecho innegable de estas dinámicas fue la consecuencia positiva sobre la continuidad cultural en la región al permitir la transmisión de prácticas, costumbres y rituales mayas yucatecos hasta nuestros días. Con esto se generó todo un proceso de reinvención cultural e identitaria que integra sus formas cotidianas de vida social, política y religiosa, producto tanto de expresiones de autodefensa en contra de la élite hegemónica, pero también de resistencia por la continuación de aspectos relevantes que otorgan sentido a sí mismos (Guzmán, 2005). Para los habitantes de esta región la milpa, el cultivo del maíz, ocupa un lugar central porque aglutina ritos, prácticas, costumbres y tradiciones de la cultura maya yucateca que han persistido y se han reelaborado o resignificado a la luz de los embates de la llamada modernidad y que hoy se explican como una "herencia maya yucateca".

Asimismo, la región maicera ha experimentado diversos procesos deexpansiónycontraccióneconómicas por factores como el crecimiento exponencial de la actividad ganadera, la comercialización de la agricultura y las limitaciones impuestas como resultado del reparto agrario ocurrido en la zona, así como por el crecimiento poblacional (Villanueva, 1997). Dedicarse al cultivo de la milpa para su propio consumo tampoco fue suficiente, de ahí que complementaran su economía con la salida de migrantes yucatecos hacia el norte de la entidad para desempeñarse en los ranchos ganaderos, o bien hacia los enclaves turísticos del vecino estado de Quintana Roo. Este cambio en la economía produjo, por supuesto, una transformación en la población trabajadora que pasó de ser agrícola a dedicarse al sector de servicios.

\section{Cancún, escenario de destino}

Para Lewin (2007), el desequilibrio económico y social en Yucatán, junto con el crecimiento urbano y demográfico y los mayores salarios que se obtenían fuera de la entidad, generaron movimientos de población tanto hacia otros puntos en el país -interregional-, como internacionalmente, y la zona maicera no fue la excepción. El éxodo hacia la capital del estado o a centros de corte turístico como Cancún o la Riviera Maya, e incluso a Estados Unidos, forma parte de la realidad que experimentan los mayas yucatecos de esta región socioeconómica. A nivel regional, el estado de Quintana Roo se coloca como el punto de atracción migratoria a nivel nacional, de acuerdo con los datos de 2010, al albergar uno de los volúmenes más alto de inmigrantes interregionales (INEGI, 2011).

Cancún, ciudad ubicada en el municipio de Benito Juárez, es uno de los puntos de destino más atractivos para la población migrante desde su constitución como centro turístico de talla mundial a inicios de la década de los setenta del siglo pasado. La población inmigrante que llegó a la ciudad procedente de otras zonas del país fue en aumento a lo largo de los años, al pasar de 29 753 en 1980, a 408857 en 2010 (INEGI, 1980; 2011). La población inmigrante yucateca ocupa el primer lugar, pues tan sólo en el municipio de Benito Juárez, donde se localiza Cancún, radican más de 125000 personas (INEGI, 2011). La preferencia de los migrantes yucatecos por dirigirse a esta región del Caribe mexicano se explica a partir de las interconexiones entre Yucatán y Quintana Roo, porque la cercanía entre ambos estados facilita el desplazamiento hacia los lugares de destino así como la posibilidad de que los migrantes sigan conectados con sus terruños (Lewin, 2007). 
El fenómeno del turismo resulta central para comprender diversos procesos que trastocan la vida de los migrantes yucatecos en esta región quintanarroense y, al mismo tiempo, cómo interviene en la recreación de sus pertenencias. Autores como Dufresne (1994), Pérez (1996) y Ramírez (2006) tratan, entre otros temas, el impacto negativo que el desplazamiento hacia esta región del oriente peninsular ha tenido sobre los migrantes mayas ocasionado por la desarticulación que experimentan comunidades del sur y oriente del estado yucateco, así como por la pérdida cultural debida a su incursión en la vida globalizada del Caribe mexicano. Por otro lado, autores como Re $(1994 ; 1996 ; 2006)$ y Rosales (2009) reafirman en sus estudios el vínculo con sus comunidades de origen porque, entre otros factores, los migrantes de la región de estudio recrean su bagaje cultural en el destino, con lo que consolidan y validan su identidad yucateca ante los embates de la modernidad que experimentan al llegar al nuevo lugar.

A pesar de considerar el turismo como un factor que perturba y desorganiza la cotidianidad de las comunidades que participan en la dinámica migratoria, es importante señalar su capacidad de generar agencia y promover la continuidad cultural. Junto con el turismo, en Cancún ha surgido una sociedad emergente, producto de las migraciones continuas y de los diversos proyectos de desarrollo en los que se han insertado los migrantes yucatecos. En la ciudad construyen su experiencia como migrantes, como yucatecos y como poseedores de la cultura maya en un entorno ajeno. Esto es posible observar en los migrantes originarios de una de las regiones yucatecas más tradicionales y con participación migratoria importante, la maicera. De estos migrantes yucatecos y sus experiencias de vida es de lo que trata el siguiente apartado.

\section{Una metodología orientada hacia el trabajo con migrantes yucatecos radicados en Cancún}

Para tratar sobre la presencia de los inmigrantes en los escenarios turísticos, donde se ponen en juego las formas de comprender el mundo a partir de reinventar los lugares de origen y de destino, en este apartado buscamos explicar cómo la segunda generación de migrantes yucatecos interactúa en el entorno de Cancún a través de sus referentes socioculturales. Se realizó un estudio de caso con un grupo de jóvenes cuyos padres de origen yucateco procedían de una región socioeconómica considerada tradicional: la zona maicera o milpera ubicada al oriente del estado de Yucatán. La selección de estos jóvenes a finales de 2011 se realizó a partir de una muestra más amplia constituida por 192 estudiantes de la licenciatura en Turismo y Gestión Hotelera de la Universidad del Caribe (UNICARIBE).

Posteriormente, aplicamos un criterio de selección más fino basado en el lugar de origen de sus padres, y optamos por aquellos cuyos dos padres eran de origen yucateco, por lo que la selección se concretó en 31 personas, es decir, un 16\% de los estudiantes que conformaban la muestra inicial. Para la discusión que aquí pretendemos realizar destacamos una característica de interés por su importancia en cuanto a procesos socioculturales. Nos referimos a la preferencia de padres yucatecos provenientes de la región maicera. ${ }^{4}$ Así, para efectuar el análisis que aquí se aborda se trabajó con nueve jóvenes universitarios, cinco mujeres y cuatro hombres, con una media de edad de 21 años, de los cuales seis nacieron en el estado de Yucatán - cuatro mujeres y dos hombres-. Con cada uno de ellos se implementó una serie de herramientas metodológicas propias del trabajo etnográfico como la entrevista a profundidad y la observación participante.

A través de las particularidades de estos jóvenes y desde sus experiencias, trataremos de comprender el papel que juegan algunos aspectos de su cultura y de la identidad social en un contexto económico basado en el ocio. Para tratar de responder a las interrogantes planteadas al inicio de este trabajo, en primer lugar abordaremos los aspectos sociales y culturales que consideramos son expresión de la "herencia maya yucateca" de la cual forman parte. Nos referimos a prácticas, costumbres y tradiciones que conforman la cotidianidad de los yucatecos y el significado que éstas asumen al incorporarse a la experiencia de vida de estos jóvenes. En segundo lugar, haremos referencia 
a la oferta que se realiza en Cancún con respecto a "lo maya", es decir, a cómo los empresarios y las agencias de operadores turísticos proyectan la cultura maya ante los visitantes, sobre todo porque el destino es ofrecido como "la puerta de entrada al Mundo Maya" a través de los medios de comunicación. En tercer lugar discutiremos sobre los referentes identitarios desde los que se sitúan estos hijos de migrantes yucatecos al colocar en la discusión cada uno de los aspectos socioculturales con los cuales fueron socializados.

\section{La herencia maya yucateca desde un escenario turístico}

\section{Prácticas, costumbres y tradiciones yucatecas}

Paraindagar sobre la primera pregunta de investigación: - ¿cuáles son las prácticas socioculturales que los jóvenes radicados en Cancún realizan con respecto a lo yucateco y lo maya? - puede afirmarse que en buena medida estos jóvenes viven o participan del entramado cultural socializado por los padres, y tienen un interés genuino por conocer e investigar sobre la cultura maya. Los elementos de la cultura maya que en especial valoran son: las costumbres, las tradiciones y las formas de comportarse y concebir el mundo, pues dichos conocimientos, que no todos poseen, les permiten "conectarse" con su entorno. De ahí el interés por indagar sobre las costumbres, las tradiciones, los rituales mayas y la medicina tradicional, entre otros aspectos que valoran de su "herencia familiar yucateca".

En el caso de Alicia, ${ }^{5}$ pese a la distancia, tanto ella como su familia se encontraban en permanente conexión con su cultura no sólo a través de las visitas periódicas al lugar de origen (Chemax, Yucatán), sino también por la recreación de prácticas y costumbres que llevaban a cabo en Cancún. Esto era posible porque contaban con un grupo de vecinos de origen yucateco, como ella lo describió:

[...] vivo a espaldas del estadio 86 [en la región 90] y la mayoría de mis vecinos son de Yucatán, y cuando se reúnen platican en maya, eso es muy padre [...] Yo lo entiendo, tuve que aprender por parte de mi abuela paterna que no habla en español, y cuando íbamos [al pueblo] tenía que entenderla y mi mamá me explicaba. Mis papás hablan maya... te digo, en las fiestas hablan maya para decirse bromas, es muy divertido... para las fiestas siempre se reúnen, agarran pretexto para la pachanga [...] este es el tipo de cosas que te divierten; como todos vienen de Yucatán, se identifican [...] (Alicia, originaria de Cancún, entrevista realizada el 22 de octubre de 2011).

Para la familia de Alicia y sus vecinos de origen yucateco, las fiestas o reuniones en Cancún junto con otras prácticas culturales como las "novenas", ${ }^{6}$ eran consideradas espacios idóneos para reproducir la lengua, al igual que las prácticas culinarias yucatecas. La importancia radicaba en contar con esos espacios donde se permitían, por ejemplo, hablar la lengua maya, además de que se trataba de un medio para el encuentro familiar. Para estar presente en los rosarios de la novena en honor a la Virgen de Guadalupe, doña Josefina, abuela materna de Alicia, llegaba expresamente a Cancún los primeros días de diciembre. Como "nochera" en una novena que realizaban sus vecinos, doña Josefina se sentía muy a gusto al participar, pues en reuniones de este tipo se habla maya y se hace un gran convivio donde se ofrece la comida ritual por excelencia, el relleno negro, lo que permite la identificación con una cultura en común, la yucateca. Entonces, la novena resulta ser el vehículo en la resignificación de los componentes socioculturales yucatecos porque se trata de un escenario de reproducción sociocultural que constituye, en palabras de Alicia, "lo que uno es".

Sobre las ceremonias y rituales mayas realizados en el lugar de destino, José, otro de los informantes que participaron en el estudio, nos habló del hetzmek. ${ }^{7}$ Este ritual doméstico se centra en una conexión cosmogónica maya que simboliza la incorporación del infante a la vida social y comunitaria a la cual pertenece (Fortuny, 2004; Guzmán, 2005; Villanueva y Prieto, 2009). Durante el ritual se preparan ciertos alimentos y se convida a todos los familiares, junto con 
los padrinos, a llevar a cabo el proceso de acuerdo con el sexo y con los meses de edad del infante. En sí, se apega a las expectativas preestablecidas en los niños y niñas conforme al sexo, de manera que en el ritual se utilizan tres piedras del comal para las niñas y los cuatro puntos cardinales de la milpa para los niños. Igualmente, la prosperidad se simboliza en la comida y las semillas de calabaza ofrecidas al padrino y al ahijado, al compás de nueve vueltas alrededor de la mesa, como ocurrió en el caso que nos mencionó José, donde él fungió como padrino.

La selección del compadre o la comadre se realiza comúnmente dentro de la familia, y la alegría festiva por incorporar a un nuevo miembro en la comunidad se acompaña de comida tradicional como relleno negro o cochinita. A la conexión cosmogónica maya de conducir el ritual en tiempo y forma acorde con la edad y el sexo del pequeño, actualmente se añaden nuevos elementos como la incorporación de libretas de buena calidad para propiciar el estudio o escogerle una profesión como médicos, contadores o maestros, entre otros. El compadrazgo ritual que aquí ocurre se ciñe de una responsabilidad a manera de guía para con el infante a lo largo de su vida y también confiere obligaciones. Así lo expresa José:

Es tan fuerte esa parte [de ser padrino de hetzmek] como si fuera padrino de bautizo [...] tienen la misma autoridad [...] Debes saludar a tu padrino de hetzmek porque es autoridad. Ambos padrinos se ven igual y [están pendientes del ahijado] por lo que le hiciera falta... [Son obligaciones y] de hecho se marca... como con mi sobrino donde su mamá, mi cuñada, le dice que me haga caso porque soy su tío y su padrino de hetzmek (José, originario de Chichimilá, entrevista realizada el 23 de febrero de 2012).

Desde la óptica de José, el compadrazgo adquiere un sentido de prestigio entre los participantes, pero de igual manera implica un compromiso para atender en todo momento las necesidades del ahijado, y es ahí donde los lazos familiares y comunitarios se consolidan (Villanueva y Prieto, 2009). Así, las prácticas, las costumbres y las tradiciones yucatecas, cuyas estructuras culturales forman parte del entramado social, fortalece la idea de pertenencia en las prácticas de los padres yucatecos de estos jóvenes donde hablar maya, preparar alimentos de la región y ser partícipes de rituales mayas conforman la participación de las nuevas generaciones en la vida y costumbres yucatecas.

No obstante, encontramos dos casos contrastantes: el de Rosa y el de Heberto, quienes a pesar de recibir la carga de costumbres, de tradiciones e incluso del idioma mismo, en su pequeño mundo doméstico, ambos poseen una débil concepción de la cultura maya yucateca. Según ellos, desde muy pequeños participaban en las fiestas patronales, en las "vaquerías" y las novenas cuando solían viajar a su lugar de origen. Pero el viaje no sólo era eso, sino que tenía implicaciones mayores, sobre todo, en hacer un cumplido a los familiares. En cuanto a la lengua maya, en la familia nuclear de Rosa no se usaba, pero la abuela materna, que vivía en una comunidad maya, sí la hablaba. En cambio, los padres de Heberto sí solían comunicarse en maya entre ellos; sin embargo, no les transmitieron a los hijos el idioma porque lo consideraban de poca importancia o utilidad en una ciudad "moderna" como Cancún. Ello, hablar una lengua indígena, para los padres de Heberto, significaría ser discriminados por el mundo de la "modernidad".

Por lo anterior, notamos la existencia de una ideología que opera para discriminar, segregar y ejercer prejuicios hacia las lenguas mexicanas por parte de la sociedad dominante, es decir, el estigma que conlleva el hablar una lengua indígena (Bastos, Cumes y Lemus, 2007; Goffman, 1986; López, 2011; Villanueva, 2008). Optar por aprender y hablar el español y dejar en el olvido la lengua maya por la poca funcionalidad que tiene en Cancún, puede traducirse como un avance, una acción enfocada en mejorar "socialmente" de acuerdo con las expectativas y lo necesario para pasar desapercibidos ante la sociedad. Es evitar la marca de atraso y pobreza con que se relaciona a los indígenas (López, 2011). Bajo estas discusiones, son estos jóvenes quienes manifiestan cierta distancia cultural con respecto a "lo yucateco". 
Pedro ANTONio Be-RAmírez, Eyder Gabriel Sima-Lozano, ADRIANA GONZÁLEZ-NERI

\section{El papel de la cultura maya en el ámbito turístico}

En las siguientes líneas, buscamos responder a la segunda pregunta de investigación: iqué prácticas de la comercialización de la cultura maya intervienen en el contexto cancunense y qué expresan los jóvenes sobre ello? La capacidad de las prácticas, las costumbres y la cosmovisión de la cultura regional se interpreta desde diversos ángulos como, por ejemplo, en la cotidianidad de los jóvenes. Así, los componentes culturales y de identidad social se inscriben bajo una nueva lógica donde la economía es lo que impera. En ese sentido, una modalidad fina para ofrecer los destinos turísticos; más allá del sol y la playa, también la encontramos en la cultura maya con sus celebraciones religiosas, creencias y visitas a sitios arqueológicos. Está claro que la mirada turística se orienta hacia el exotismo y el calor de las playas caribeñas, y lo que menos importa es la conservación cultural maya en su esencia en sus descendientes actuales.

En esta vertiente, la legislatura yucateca presentó el Decreto $391^{9}$ para declarar el año 2012 como "Año de la Cultura Maya” en celebración del fin del calendario maya. Por su parte, el Gobierno Federal presentó el Programa Mundo Maya con la finalidad de promover los sitios turísticos, culturales, arqueológicos y naturales, en los cinco estados del país donde se sitúan los mayas, como una forma de generar ingresos económicos (Meré y López, 2011). El municipio de Benito Juárez donde se localiza Cancún, a pesar de quedar fuera del programa oficial en un inicio, organizó sus propios eventos para promover la zona hotelera a través de torneos, regatas y conciertos de talla internacional (Moguel, 2012). Pero al revisar la serie de actividades preparadas, la ausencia de los mayas en el festejo se hizo notable. Ante este panorama, surge un cuestionamiento sobre el papel de la cultura maya para indagar si se trata de una importancia real sobre "lo maya" o bien, únicamente una estrategia para comercializar y atraer a los turistas:

Yo digo que es marketing porque no le dan proyección a las ruinas arqueológicas de El Rey o El Meco [aquíen Cancún]. Igual recuerdo que en [un hotel de la zona
PRÁCTICAS SOCIOCULTURALES, TURISMO E IDENTIDAD ENTRE LOS HIJOS DE MIGRANTES YUCATECOS EN CANCÚN

hotelera], en la parte de arriba [de sus muros] tiene jeroglíficos mayas y porque tenían una conexión con esa parte del hotel [ya estaban hablando de lo maya], pero era para aparentar porque el inmueble ya estaba y el hotel sólo lo aprovechó, le cayó como anillo al dedo [...] (José, originario de Chichimilá, entrevista realizada el 23 de febrero de 2012)

[...] puede ser un poco de [preservar y también vender] porque en estos últimos años sí ha incrementando muchísimo el turismo cultural [...] en parte es como estratégica que preservemos la costumbre para podérsela enseñar a los turistas, tal vez pueda ser eso. Sí están procurando que no se pierda el hablar maya, las tradiciones, la comida y todo eso como para dejar un legado aún más fuerte, pero también para que esa característica de nosotros atraiga más turistas $[. .$.$] tiene que ver con un interés turístico$ (Rosa, originaria de Valladolid, entrevista realizada el 13 de marzo de 2012).

Lo veo como una forma de atraer turistas. Antes Cancún era [un destino] de sol y playa, ahora quieren venderlo como un destino cultural. Es algo imposible de hacer y es algo tonto que le hace México como promoción para solventar y existir el destino. Se apoyan en la cultura maya aunque aquí no hay nada cercano... quizá las ruinas arqueológicas de El Rey, pero tampoco son muy vendidas [...] (Heberto, originario de Cancún, entrevista realizada el 26 de marzo de 2012).

Según los testimonios de jóvenes mayas la discusión va en un doble sentido. Por un lado, se crea cierta importancia para "conservar" y "mantener" la cultura de la región, pero también, si existiera un interés real, se contaría con acciones que promovieran las costumbres o el aprendizaje de la lengua maya, por ejemplo. Se cuenta con circuitos culturales donde los turistas experimentan la cultura de los mayas prehispánicos a través de visitas a sitios arqueológicos como Tulum en Quintana Roo o Chichen Itzá en Yucatán. La estrategia se basa en "continuar" ese legado de "lo maya" donde 
Pedro antonio Be-Ramírez, Eyder Gabriel Sima-Lozano, ADRIANA GONZÁLEZ-NERI
PRÁCTICAS SOCIOCULTURALES, TURISMO E IDENTIDAD ENTRE LOS HIJOS DE MIGRANTES YUCATECOS EN CANCÚN las cadenas hoteleras, restauranteras y del espectáculo junto con instancias gubernamentales, ofrecen ciertos performances como productos "mayas". Empero, más que basarse en una real expresión de lo maya, se trata de una reinvención por parte de las empresas turísticas y del gobierno para atraer más turistas. Además, se pretende la apropiación simbólica de lo maya por parte de las agencias y las empresas de turoperadores para crear una "economía simbólica" como lo refiere Meethan (2001) destinada a la satisfacción del ocio de los visitantes.

Sin duda, el objetivo es vender, así de simple. De manera que los elementos culturales se transforman en productos turísticos para el consumo de los visitantes (Telfer y Sharpley, 2008; Wall y Mathieson, 2006). Pese a enaltecer el pasado de los mayas como constructores de majestuosas pirámides, los actuales poseedores de dicha cultura, es decir, los mayas de carne y hueso carecen de participación en la toma de decisiones de sus necesidades y expectativas. Los mayas se convierten ante los ojos de los turistas en imágenes cargadas de tradición y exotismo. La acción de los nativos locales se limita a ciertos escenarios en los que se les concibe como "objetos culturales" de ahí que la experiencia única sobre "lo maya" sea una marca comercial como afirma Monterrubio (2013), y se coloque lo vistoso y lo exótico a favor del interés, los deseos y la satisfacción del turismo. Es pues, desde la óptica de Urry (2002), esa "mirada turística" construida para los visitantes que resulta interesante inquirir cómo los jóvenes hijos de migrantes yucatecos en Cancún ponen en entredicho esta noción de concebir y ofrecer la cultura maya hacia "los otros".

\section{La identidad, procesos de identificación y diferenciación}

Al tomar en cuenta la socialización recibida en el ámbito doméstico y las experiencias obtenidas tanto en origen como en destino, buscamos respuesta a la tercera pregunta: icómo construyen los jóvenes su identidad a partir de la experiencia con su origen y el escenario actual? Para responder esto, encontramos entre los jóvenes tres entornos para construir sus pertenencias de manera particular. El primero se presenta en aquellos que nacieron en Cancún. En ellos resulta innegable la conexión con el lugar de origen, pues además de asumir su identidad con respecto a su territorialidad ("soy de Cancún"), añaden el bagaje cultural heredado de sus padres. Aunque nacieron en un lugar turístico, ellos retoman la cultura maya yucateca como su pertenencia inicial y reiteran su lugar de nacimiento por cuestiones jurídicas manifestadas en los registros donde las actas y cartillas de identificación lo comprueban. Ello se expresa en el siguiente testimonio:
Yo nací aquí en Cancún, por acta de nacimiento soy quintanarroense, cancunense, pero soy de sangre yucateca. Me considero yucateco aunque haya nacido aquí... por cuestiones jurídicas soy quintanarroense... tampoco soy de esas personas que rechaza sus orígenes porque mis papás son de ahí (Heberto, originario de Cancún, entrevista realizada el 26 de marzo de 2012)

La capacidad de reinvención identitaria es patente en el testimonio de Heberto, pues además de expresarse como cancunense también se identifica como "de sangre yucateca" a través de las costumbres y las creencias que le dan solidez a sus raíces yucatecas. En el caso de Alicia, hablar de Yucatán, de su gente, su trato, sus historias y leyendas, su tranquilidad, e incluso su forma tan particular de hablar, corresponden a la vida cotidiana dentro de su núcleo familiar y de las relaciones comunitarias que se han formado con sus vecinos, con quienes comparte el mismo código cultural, lo que le permite sentirse como si estuviera en el origen. En este orden de ideas, hallamos en los testimonios que el lugar de donde proceden sus padres es su primer referente. Marisol, otra informante, nos suministra un ejemplo de ello:

[Soy] una yucateca que va a seguir siendo y será de ahí... viviendo en Cancún, en donde sea, siempre realizaré lo mismo, todo, las tradiciones que me ha enseñado mi papá de Yucatán. Si me voy a otro lugar, si me caso, [a mis hijos] les voy a enseñar lo que yo sé, soy de Yucatán, soy yucateca... sí, porque a veces dicen “los indios de Yucatán” y no, no son indios, 
son más inteligentes que tú viendo todo lo que han hecho, y hasta digo que me considero con suerte por haber nacido ahí, así es... iAsí soy! iSoy una yucateca! iTodo lo que tenga que ver de ahí, soy yo! (Marisol, originaria de Valladolid, entrevista realizada el 13 de marzo de 2012).

La valoración del "ser yucateca”, en el caso de Marisol, refleja la continuidad de tradiciones y costumbres inculcadas por sus familiares. Para ella, resulta afortunado haber nacido en Yucatán donde todo ese bagaje cultural aprendido a través de sus padres y por cuenta propia, constituye su referente más importante. Estas concepciones se acompañan de la grandeza que reside en la cultura maya, y de ser portadores de majestuosas construcciones arqueológicas, de conocimientos sobre medicina, del clima y la naturaleza que reflejan la etnicidad maya (Cumes y Lemus, 2007 y Villanueva, 2008).

Así, esta pertenencia orientada hacia el pasado y las identidades indígenas en las que los informantes tienen un sentimiento de pertenencia (Oehmichen, 2005; Romer, 2009), explica lo que en ellos reside, según José: "seguir siendo lo que uno es y no perderlo", aunque esta pertenencia cultural no está exenta de la diversidad de Cancún; influye en el contrapeso atribuido tanto al origen como al destino. Así lo menciona Rosa:

iAy, Dios! No sé (se ríe), así en cierta manera no sé qué decir porque conozco mucho de Valladolid, podría ser la mitad y mitad. iNo!, más cancunense que de Valladolid porque toda mi vida es de aquí, aunque Cancún no tenga una identidad [...] y en cuanto a Valladolid [...] me encanta que mi familia sea de ahí, siempre junta, dando buenos valores y gracias a ellos soy lo que soy aunque viva aquí en Cancún. Entonces me considero parte de Cancún un 70,75 por ciento y el resto de Valladolid. Una preferencia por los dos no, antes te hubiera dicho 100 por ciento cancunense, pero por muchas cosas ya me siento más aquí, pero un poquito de allá [...] (Rosa, originaria de Valladolid, entrevista realizada el 13 de marzo de 2012).
Mientras los demás jóvenes hacen alusión a la cultura de origen de los padres, para Rosa su referente se sitúa, esencialmente, en la ciudad de Cancún, el cual considera como el espacio donde elabora su presente. No obstante, la visita ocasional a su familia en el lugar de origen contribuye a enriquecer la "otra parte" de su cultura. Su "nuevo" acercamiento identitario que media entre Cancún y Valladolid es producto de las reflexiones y discusiones generadas sobre la cultura regional que recibió en su formación universitaria. Esto podríamos sustentarlo en la idea de Romer (2009) acerca de la diversidad de los hijos de migrantes yucatecos.

Otro punto del análisis es la ausencia de una identidad propia en Cancún, atribuida a la inexistencia de costumbres, tradiciones locales, aunque algunos autores indican que ésta se encuentra en construcción (Escalona, 2010; Jiménez y Sosa, 2008; Oehmichen, 2010). Un ejemplo que sirve para objetar este concepto, es el caso de Rosa, quien afirma que este polo turístico no posee una identidad común ni mucho menos generalizable, y aun así se identifica como cancunense. La distancia, con respecto a su bagaje cultural, se explica por sus referentes acordes con el lugar de destino donde se vive la "modernidad", pues las costumbres, las formas de pensar y la cotidianidad de Valladolid, no tienen cabida en sus propias visiones y en sus actividades diarias. La globalización junto a la diversidad cultural experimentada en Cancún sacan a la luz la incompatibilidad con otros pueblos y ciudades de la Península de Yucatán.

\section{A manera de conclusión}

En este trabajo, hemos expuesto la manera en que la segunda generación de migrantes yucatecos se relaciona e interactúa en el lugar de destino, donde los significados, y las concepciones de vivir y ubicarse en un polo turístico cobran importancia para ellos. Para lograr el objetivo planteado en la introducción, respondimos tres cuestionamientos propuestos al inicio de este escrito sobre las prácticas socioculturales mayas yucatecas, la comercialización de dichas prácticas en sitios precolombinos orientados hacia el turismo 
Pedro antonio Be-Ramírez, Eyder Gabriel Sima-Lozano, ADRIANA GONZÁLEZ-NERI
PRÁCTICAS SOCIOCULTURALES, TURISMO E IDENTIDAD ENTRE LOS HIJOS DE MIGRANTES YUCATECOS EN CANCÚN nacional o internacional, y las construcciones que de sí mismos elaboran los informantes a partir de situarse en el escenario de sol y playa. Sobre estos encuentros, al que los hijos de migrantes yucatecos han asistido, se demuestran las nuevas formas de apropiación y reinterpretación del mundo individual y colectivo.

Lo que se ilustra en este trabajo advierte sobre los eventos sociohistóricos acontecidos en el sureste mexicano, sobre todo, el impacto del turismo entre los yucatecos, quienes contribuyeron a la creación y consolidación de una región de talla mundial como es el Caribe mexicano. La socialización y la constante recreación cultural permiten la continuidad de prácticas, costumbres y tradiciones como el hetzmek, las novenas o la lengua maya. Empero, el hecho de que los padres provengan de una zona tradicional como es la maicera no se traduce en una reproducción cultural de facto en el lugar de destino. Así, se observa el uso de la lengua maya en hablantes adultos como los padres y abuelos, no así entre los jóvenes que marcan diferencias entre el lugar de origen y el lugar del destino.

Sobre estos jóvenes podemos advertir la importancia de estar conectados con "lo yucateco" donde es posible preparar alimentos yucatecos, escuchar la lengua maya e incluso participar de ciertos rituales como el hetzmek. Ello no significa una incorporación inmediata y absoluta en tales prácticas, rituales o costumbres mayas yucatecas. La vida habitual de Cancún comprende, entre los jóvenes que conforman este estudio de caso, una reinterpretación de sus experiencias y formas de entender el mundo en el marco de la modernidad, pero también del racismo y la discriminación. Es en esa interacción donde cada uno determina la importancia de hablar la lengua maya, la convivencia y la interacción con los paisanos en el destino. Desde este panorama, eligen ser como los yucatecos, pues se realiza una reinvención hecha a la medida de las circunstancias entre el lugar de origen y el espacio del destino.

Cancún es una ciudad donde la complejidad está a la orden del día, por lo que la reinvención cultural entre los migrantes yucatecos y su incorporación en el atrayente mercado global costero quintanarroense, son el mecanismo para cautivar a los turistas extranjeros.
El Caribe mexicano constituye un nicho de análisis y reflexión, donde la innegable presencia de la cultura maya y las relaciones interétnicas conforman la base para indagar la presencia de los mayas yucatecos o bien de otros mexicanos, de turistas nacionales o extranjeros, quienes le imprimen un sello particular al entorno turístico global.

De manera particular, resulta relevante el encuentro entre los migrantes y los locales, específicamente entre los yucatecos y quienes no lo son, pues es el reflejo de las transformaciones o reinvenciones sobre las prácticas, costumbres y valores yucatecos en aquellos escenarios donde se 'consume' su cultura. En definitiva, desde estas trincheras es posible apreciar las representaciones e imaginarios sobre la cultura maya y el papel que presentan los mayas actuales ante las instancias de control y superioridad en pos de la modernidad y la globalización.

\section{Notas}

${ }^{1}$ Empleamos la estrategia conceptual de segunda generación para caracterizar a los hijos de las personas que residen en un lugar diferente al de su origen, se trata pues de población migrante (Fortuny, 2004). Con fines heurísticos, pese a tratarse de una noción controversial, aprovechamos el concepto para referirnos a los hijos nacidos en la ciudad de acogida así como de aquellos que llegaron al destino en los primeros años de vida.

${ }^{2}$ Al tratar sobre la construcción social de la identidad en Yucatán, resulta inevitable denotar la complejidad que conlleva dicha cuestión. A través del tiempo se han presentado diversas formas para referirse a los habitantes de la entidad ya sea como mayas (que comúnmente se refieren a aquellos que construyeron las pirámides), mayeros (por hablar la lengua maya) o mestizos (por usar la indumentaria tradicional así como por el cruce racial y cultural durante la colonia), y aun así, los límites entre uno y otro se vuelven permeables. Los procesos históricos, sociales y culturales, como lo ha señalado Be (2011), son elementos centrales para caracterizar la identidad en Yucatán como maya, mayero, mestizo o mayayucateco, y cuyos intercambios han 
desvanecido las diferencias identitarias complejizando aun más la identificación. Se puede decir que la población yucateca mantiene sus referentes identitarios bajo una cultura maya yucateca resignificada.

3 Además de la región maicera, existen cuatro zonas más en la entidad: la henequenera, la citrícola, la ganadera y la correspondiente al litoral pesquero. Si bien esta regionalización no es única y mucho menos definitiva, nos permite entender tales áreas considerando sus aspectos sociales, económicos y políticos que les caracterizan (Cf. Villanueva, 1990).

${ }^{4}$ De acuerdo con los datos obtenidos, aquellos padres que proceden de la zona maicera conforman el treinta por ciento de la muestra. Según la distribución realizada por región socioeconómica en Yucatán, la zona que ocupa el primer sitio corresponde a los padres que proceden de la región ex henequenera con un cincuenta y dos por ciento, le sigue la ganadera con un once por cierto y en menor medida, la zona del litoral-pesquero y la citrícola con un cinco y dos por ciento, respectivamente.

5 Para guardar la confidencialidad de los jóvenes decidimos modificar sus nombres.

${ }^{6}$ Con un carácter más doméstico, la novena o novenario se refiere al rezo del rosario por nueve días, de ahí su nombre. El dueño o dueña del santo o virgen a quien se dedica la novena, invita a otras personas (familiares principalmente además de vecinos y otros conocidos) a ser nocheros, nombre debido a que el rosario se realiza por las noches. Los nocheros son quienes se hacen cargo de uno de los días de la novena al colaborar con las flores, velas y en el refrigerio que se ofrece al concluir el rosario conocido como el toch.

${ }^{7}$ El ritual doméstico del hetzmek tiene el propósito de integrar al infante a la vida en comunidad, prepararlo para que en un futuro sea un adulto de provecho. Se trata de un rito de paso o iniciación el cual se ha reinventado con el paso del tiempo, aunque su propósito principal aún persiste (Fortuny, 2004; Villanueva y Prieto, 2009).

${ }^{8}$ La vaquería es la fiesta tradicional yucateca cuyo origen se remonta a la época colonial y es la celebración inicial con que se abren los festejos del pueblo, siendo el momento cuando las mujeres portan sus mejores atuendos llamados ternos o vestidos de gala y los hombres se visten a la usanza tradicional de mestizos, con pantalón, guayabera blanca y alpargatas como calzado.

${ }^{9}$ Dicho decreto se expidió el 11 de marzo de 2011, bajo el mandato de la exgobernadora Ivonne Ortega Pacheco.

\section{Referencias Bibliográficas}

Barth, Fredrik (1976). “Introducción”. En Fredrik Barth (ed.), Los grupos étnicos y sus fronteras. La organización social de las diferencias culturales. México: Fondo de Cultura Económica, pp. 9-49.

Bartolomé, Miguel Alberto (2006). Gente de costumbre y gente de razón. Las identidades étnicas en México. (3ª. ed.). México: Siglo XXI.

Bastos, Santiago, Aura Cumes y Leslie Lemus (2007). Mayanización y vida cotidiana. La ideología multicultural en la sociedad guatemalteca. Guatemala: FLACSO, CIRMA, Cholsamaj.

Be Ramírez, Pedro Antonio (2011). "Dimensiones culturales e identidades situadas: la herencia maya en migrantes yucatecos a Estados Unidos". En Estudios de Cultura Maya, 38, otoño-invierno: 167-192.

Dufresne, Lucie (1994). "Evolución de la región maya e impactos del turismo en la Península de Yucatán”. En Revista de la Universidad Autónoma de Yucatán, 9(190), julio-agosto-septiembre: 58-67.

Dumond, Don E. (2005). El machete y la cruz. La sublevación de campesinos en Yucatán. México: Universidad Nacional Autónoma de México, Plumsock Mesoamerican Studies, Maya Educational Foundation.

Escalona Hernández, Concepción (2010). "La construcción de identidad en Cancún”. En Concepción Escalona Hernández (coord.), Cancún: un entramado de voces, cultura, sociedade historia. México: Universidad del Caribe, pp. 76-97.

Fortuny Loret de Mola, Patricia (2004). "Transnational hetzmek: entre Oxkutzcab y San Pancho". En Juan A. Castillo Cocom y Quetzil E. Castañeda (eds.), Estrategias identitarias. Educación y la antropología histórica en Yucatán. Mérida, Yucatán: Universidad Pedagógica Nacional Unidad 31-A, The Open School of Ethnography and Anthropology, Secretaría de Educación Pública, pp. 225-254. 
Pedro antonio Be-Ramírez, Eyder Gabriel Sima-Lozano, ADRIANA GONZÁLEZ-NERI
PRÁCTICAS SOCIOCULTURALES, TURISMO E IDENTIDAD ENTRE LOS HIJOS DE MIGRANTES YUCATECOS EN CANCÚN
Giménez, Gilberto (1997). "Materiales para una teoría de las identidades sociales". En Frontera Norte, 9(18), juliodiciembre: 9-28.

Giménez, Gilberto (2007). Estudios sobre la cultura y las identidades sociales. México: Consejo Nacional para la Cultura y las Artes, Instituto Tecnológico y de Estudios Superiores de Occidente.

Goffman, Erving (1986). Estigma. La identidad deteriorada. Buenos Aires: Amorrortu.

Guzmán Medina, María Guadalupe Violeta (2005). Una nueva mirada hacia los mayas de Yucatán. Identidad, cultura y poder. Mérida, Yucatán: Universidad Autónoma de Yucatán.

INEGI (1980). Censo general de población y vivienda 1980. Tabulados básicos. Quintana Roo. México: Instituto Nacional de Estadística y Geografía.

INEGI (2011). Principales resultados del Censo de Población y Vivienda 2010. Quintana Roo. México: Instituto Nacional de Estadística y Geografía.

Jiménez Martínez, Alfonso de Jesús y Priscila Sosa (2008). "Cocktail Cancún: reflexiones sobre los impactos sociales del turismo en la comunidad local". En Maribel Osorio García y Marcelino Castillo Nechar (coords.), Entorno del turismo. Perspectivas, vol. 3. Toluca, México: Universidad Autónoma del Estado de México, pp. 63-109.

Lewin Fischer, Pedro (2007). "Yucatán as an Emerging Migrant-Sending Region”. En Wayne Cornelius, David Fitzgerald y Pedro Lewin Fischer (eds.), Mayan Journeys. The New Migration from Yucatán to the United States. La Jolla, California: Center for Comparative Immigration Studies, pp. 1-26.

López Santillán, Ricardo (2011). Etnicidad y clase media. Los profesionistas mayas residentes en Mérida. México: Universidad Nacional Autónoma de México, Instituto de Cultura de Yucatán.

Meré Vega, Dayna y Mayolo López (2011). “Anuncia FCH plan turístico para sureste". En Terra.com.mx, 21 de junio. Disponible en http:/www.terra.com.mx/noticias/ articulo/1l39965/Anuncia+FCH+plan+turistico+para+ sureste.htm (consultado el 17 de abril de 2012).

Meethan, Kevin (2001). Tourism in Global Society. Place, Culture, Consumption. Malasia: Palgrave.
Moguel, Renán (2012). “Anuncian 250 eventos para el programa Mundo Maya. El titular de la OVC dio a conocerqueeldos demayo sereuniráconlosprincipales operadores turísticos norteamericanos para difundir los eventos". En Sipse.com, 26 de abril. Disponible en http://sipse.com/noticia.php?ID_NOTICIA=154695 (consultado el 24 de septiembre de 2012).

Monterrubio Cordero, Juan Carlos (2013). Turismo no convencional. Impactos socioculturales. México: Trillas.

Oehmichen Bazán, Cristina (2005). Identidad, género y relaciones interétnicas. Mazahuas en la ciudad de México. México: Universidad Nacional Autónoma de México-Instituto de Investigaciones AntropológicasPrograma Universitario de Estudios de Género.

Oehmichen, Cristina (2010). "Cancún: la polarización social como paradigma en un México Resort". En Alteridades, 20(40), julio-diciembre: 23-34.

Pérez Taylor, Rafael (1996). Entre la tradición y la modernidad. Antropología de la memoria colectiva. México: Universidad Nacional Autónoma de México.

Quintal Avilés, Ella Fanny (2005). “Way yano’one’: aquí estamos. La fuerza silenciosa de los mayas excluidos". En Miguel A. Bartolomé (coord.), Visiones de la diversidad. Relaciones interétnicas e identidades indígenas en el México actual, vol. II. México: Instituto Nacional de Antropología e Historia, pp. 291-371.

Quintal, Ella F., Juan Carlos Bastarrachea, Fidencio Briceño, Martha Medina, Renée Petrich, Lourdes Rejón, Beatriz Repetto y Margarita Rosales (2003). "Solares, rumbos y pueblos: organización social de los mayas peninsulares". En Saúl Millán y Julieta Valle (coords.), La comunidad sin limites. Estructura social y organización comunitaria en las regiones indígenas de México, vol. I. México: Instituto Nacional de Antropología e Historia, pp. 293-382.

Ramírez Carrillo, Luis Alfonso (2006). "Impacto de la globalización en los mayas yucatecos”. En Estudios de Cultura Maya, 27, primavera-verano: 73-97.

Re Cruz, Alicia (1994). "Lo sagrado y lo profano de la identidad maya entre los emigrantes de Yucatán". En Nueva Antropología, 14(46): 39-48.

ReCruz, Alicia (1996). "Una comunidad maya de Yucatán: transformación social y expresión simbólica”. En Revista Española de Antropología Americana, 26: 167-181. 
Re Cruz, Alicia (2006). "Turismo y migración entre los mayas de Yucatán. Las nuevas milpas de Chan Kom”. En Revista Española de Antropología Americana, 36: 149162.

Romer, Marta (2009). ¿Quién soy? Estrategias identitarias entre hijos de migrantes indígenas. México: Instituto Nacional de Antropología e Historia.

Rosales Mendoza, Adriana Leona (2009). “Concepciones culturales, género y migración entre mayas yucatecos en Cancún, Quintana Roo". En Estudios de Cultura Maya, 33, primavera-verano: 105-120.

Telfer, David J. y Richard Sharpley (2008). Tourism and Development in the Developing World. Londres: Routledge. Urry, John (2002). The Tourist Gaze. (2ª ed.). Londres: Sage Publications.

Villanueva Mukul, Eric (1990). La formación de las regiones en la agricultura. (El caso de Yucatán). Mérida, Yucatán: Maldonado Editores, FCA-UADY, CEDRAC A. C.
Villanueva Mukul, Eric (1997). “La zona milpera de Yucatán: perspectivas para su desarrollo sustentable”. En Luisa Paré, David B. Bray, John Burstein y Sergio Martínez Vázquez (comps.), Semillas para el cambio en el campo: medio ambiente, mercados y organización campesina. México: Universidad Nacional Autónoma de México-Instituto de Investigaciones Sociales, La Sociedad de Solidaridad Social "Sasekan Tinemi", Servicios de Apoyo Local al Desarrollo de Base en México, A.C., pp.167-179.

Villanueva Villanueva, Nancy (2008). "La revaloración de la cultura maya en Yucatán”. En Temas Antropológicos, 30(2): 79-108.

Villanueva Villanueva, Nancy Beatriz y Virginia Noemí Prieto (2009). "Rituales de hetzmek en Yucatán". En Estudios de Cultura Maya, 33, primavera-verano: 73-103. Wall, Geoffrey y Alister Mathieson, (2006). Tourism: Change, Impacts and Opportunities. Toronto: Pearson Prentice Hall. 